\title{
Short communication: Technologies and milking practices that reduce hours of work and increase flexibility through milking efficiency in pasture-based dairy farm systems
}

\author{
J. P. Edwards, ${ }^{1 *}$ ๑ B. Kuhn-Sherlock, ${ }^{2}$ 이 B. T. Dela Rue, ${ }^{2}$ and C. R. Eastwood ${ }^{1} \oplus$ \\ ${ }^{1}$ DairyNZ Ltd., PO Box 85066, Lincoln University, Lincoln 7647, New Zealand \\ ${ }^{2}$ DairyNZ Ltd., Private Bag 3221, Hamilton 3240, New Zealand
}

\begin{abstract}
To attract and retain quality employees, dairy farms must be competitive with other workplaces offering more conventional hours of work. Milking requires significant labor input and influences the start and end times of the working day, affecting flexibility to suit employee needs or availability. The use of labor-saving technology and milking management strategies could help with this challenge. Previous studies have used scenario modeling in attempt to quantify the value of in-parlor technologies, however, they have relied on assumptions about the effect of the technologies on labor in the dairy. Similarly, the effect of management strategies on work patterns, such as flexible milking intervals (changing the timing of milking), has not been evaluated. The aims of this study were to (1) quantify the milking labor requirements in a range of pasturebased dairy farm systems and (2) identify practices or technologies that facilitate efficient milking. A telephone survey of 500 dairy farmers in New Zealand was conducted during April and May 2018, with questions asked about milking practices and technology use. Predictive analysis showed that at peak lactation, milking required between 17 and $24 \mathrm{~h} /$ wk per worker for farms milking twice a day, representing 43 to $58 \%$ of a conventional 40-h work week, depending on parlor type (herringbone or rotary), the number of clusters, and herd size. Using milking intervals of 8 and $16 \mathrm{~h}$ (intervals between milkings), compared with the more usual 10 and $14 \mathrm{~h}$, largely avoided starting milking before 0500 h. Eight percent of herds were milked once a day, which required between 7 and $14 \mathrm{~h} /$ wk per worker (18-35\% of a 40-h week). ANOVA showed that for metrics that related to people (labor efficiency and work routine), using automatic teat spraying had a positive effect on efficiency. Having both automatic cluster removers and
\end{abstract}

Received November 21, 2019.

Accepted March 27, 2020.

*Corresponding author: Paul.Edwards@dairynz.co.nz drafting were associated with longer milking times in terms of throughput and row/rotation time compared with using drafting only. The results highlight considerable opportunity to reduce the number of hours those milking (employers and employees) spend in the parlor and increase staff time flexibility through milking (e.g., intervals between milkings) and parlor management (e.g., row/rotation time) and use of specific technologies. This study provides useful data for those wishing to analyze the likely value of an in-parlor automation technology or management practice for an individual situation.

Key words: labor, parlor, milking intervals, technology

\section{Short Communication}

To attract and retain quality employees, dairy farms must be competitive with other workplaces offering more conventional hours of work. Recently, the importance of this was acknowledged in New Zealand, with a commitment to build great workplaces for the most talented workforce (Dairy Tomorrow, 2018), and in Ireland, through the People in Dairy Action Plan (Teagasc, 2018).

In the last decade there has been a significant amount of research to improve the efficiency of conventional milking in pasture-based dairy farm systems (O'Brien et al., 2012; Edwards et al., 2013c, 2014a). The largest body of work has focused on end-of-milking processes (Jago et al., 2010; Burke and Jago, 2011; Edwards et al., 2013a, 2013b). The context for these studies had been an increase in herd sizes (LIC and DairyNZ, 2019), a desire to manage the herd without increasing labor costs, and the knowledge that up to $57 \%$ of farm labor is used for milking (Taylor et al., 2009).

A greater use of technology is one approach to reduce work hours and increase flexibility (Eastwood et al., 2018), but the uptake of some technologies, such as automatic teat spraying in herringbone parlors, remains low (Dela Rue et al., 2019). This may be due to uncertainty about the value proposition of some tech- 
Table 1. List of questions asked of farm owners or decision makers relating to milking management and technology use

\begin{tabular}{ll}
\hline $\begin{array}{l}\text { Question } \\
\text { number }\end{array}$ & Survey question \\
\hline 1 & What was the maximum number of cows milked at peak production this season $?^{1}$ \\
2 & What type of cow shed do you have? \\
3 & How many sets of cups do you have in the cow shed? \\
4 & How many people in total, including yourself, are required to run the farm over the season? \\
5 & How many people, including yourself, are required in the shed to milk the herd at peak, excluding getting the cows in? \\
6 & How many times a day was the herd milked at the peak of production? \\
7 & Thinking about peak of production again, what is the typical start time and end times for each milking? ${ }^{2}$ \\
8 & I have a list of automated equipment and technologies that I'm going to read out, and ask if you have them in your shed: \\
& - Automatic cup removers? \\
& - Automatic drafting system?
\end{tabular}

${ }^{1}$ Peak production in block calving systems was chosen because that is when milking times are longest, which influences the number of workers on the farm.

${ }^{2}$ Milking was defined as the time the first cluster was attached until the last cluster was removed; interviewers therefore recorded the start and end of the morning milking, and start and end time of the afternoon milking.

${ }^{3}$ An automatic teat sprayer was defined as a device that automatically senses a cow and applies teat spray, for example, a walk-over device on the exit lane or mounted to the rotary platform one bail before the exit; the majority of farms without an automatic teat sprayer were likely spraying manually (Edwards et al., 2015).

nologies or combinations of technologies (Rutten et al., 2018; Thomas et al., 2019). Previous studies have used scenario modeling in an attempt to quantify the value of in-parlor technologies in terms of labor saved and therefore, economics (Tarrant and Armstrong, 2012; Edwards et al., 2014a). However, these studies rely on assumptions about the effect of the technologies on labor in the dairy. We are not aware of any study that has attempted to identify relationships between individual in-parlor technologies and labor requirements or milking efficiency. Furthermore, the effect of management strategies, such as flexible milking intervals (O'Brien et al., 1998), which could improve workplace attractiveness, have not been evaluated on commercial farms. The investigation of these aspects also provides an opportunity to assess labor requirements at milking to determine whether it should remain a focus area for industry investment to improve workplace attractiveness in pasture-based dairy systems.

To better understand factors affecting the value proposition of milking-related technologies and management practices, the aim of this study was to a) determine the milking labor requirements in pasture-based dairy farm systems and b) identify practices or technologies that facilitate efficient milking.

A telephone survey of dairy farmers in New Zealand was conducted during April and May 2018, as described by Dela Rue et al. (2019). Briefly, contact details were randomly selected from the Livestock Improvement Corporation (Hamilton, New Zealand) customer database. Due to differences in the prevalence of herringbone (69\% of the database) and rotary (30\% of the database) milking parlors (other parlor types were $1 \%$ and were not surveyed), which have significant operational differ- ences, the survey over-sampled rotary parlors to ensure a sufficient sample size to draw conclusions about each parlor type. In New Zealand, herringbone parlors are typically $50^{\circ}$ swing-over design (without rapid-exit and stanchion bailing) and rotaries are typically external design. A total of 248 and 252 responses were received, and 239 and 245 responses used in the analyses, from farmers with herringbone and rotary dairies, respectively. The full survey consisted of 66 questions, of which a subset of 8 related to milking practices at peak lactation were used in this study (Table 1).

Using the answers to these questions, a series of 7 metrics were calculated. (1) Total daily milking duration (h) was calculated for each responding farmer by subtracting the milking start time from the milking end time for each milking, and summing the result for all milkings in a 24-h period. (2) The average number of hours spent milking per week per farm worker (h/wk per worker) was calculated by multiplying total daily milking duration by the number of people in the parlor milking, multiplied by 7 , and divided by the total number of farm workers. (3) The milking intervals (h) for farms that milked twice a day (TAD) were calculated by subtracting the milking start time of the morning milking from the start time of the afternoon milking. (4) Throughput (cows milked per $\mathrm{h}$ of milking) was calculated for each milking by dividing the number of cows milked, by the end milking time minus the start milking time. (5) Throughput per person milking was calculated by dividing throughput (see 4) by the number of people milking. It was assumed that the number of people milking at each milking during the day was constant. (6) Row (herringbone) or rotation (rotary) time (min) was calculated by dividing 60 (the number 
Table 2. Coefficients for significant factors affecting a range of milking efficiency metrics, from a generalized linear model analysis ${ }^{1}$

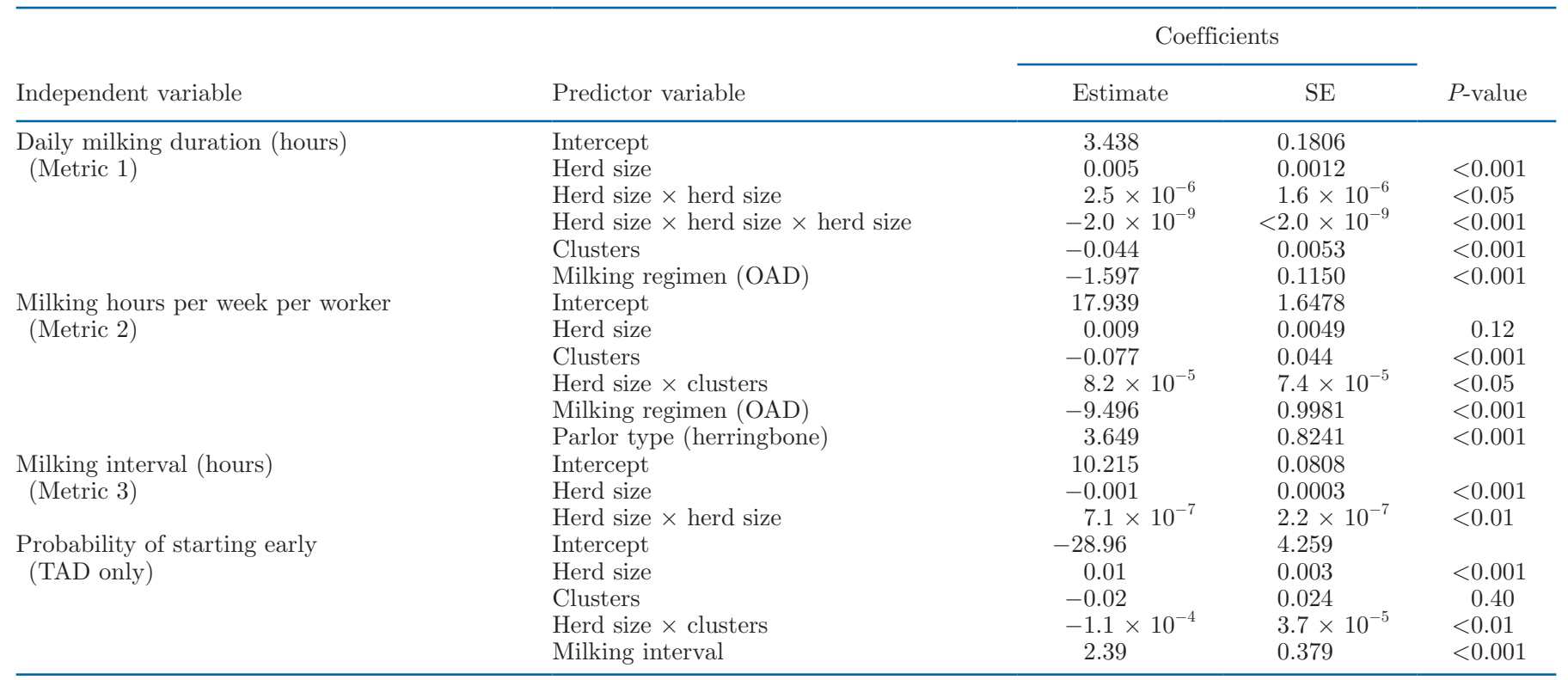

${ }^{1} \mathrm{OAD}=$ milked once a day; $\mathrm{TAD}=$ milked twice a day

of minutes in an hour) by throughput and multiplying this by the number of clusters in the parlor. (7) The work routine time (seconds/cow per person) was calculated by dividing 3,600 (the number of seconds in an hour) by throughput per person milking. This metric was only calculated for herringbone parlors because cow loading and exiting is automated in rotary parlors but not usually in herringbone parlors.

The average herringbone parlor had 28 clusters $( \pm 10$; standard deviation), and at peak lactation was used to milk a $316( \pm 145)$ cow herd, taking $3.8( \pm 1)$ h per day and requiring $20.4( \pm 6.9) \mathrm{h} /$ wk per worker. In comparison, the average rotary parlor had $48( \pm 12)$ clusters and was used to milk a herd of $619( \pm 293)$ cows, taking $4.8( \pm 1.5) \mathrm{h}$ per day and requiring $17.1( \pm 6.5) \mathrm{h} /$ wk per worker. In terms of milking efficiency metrics, the average throughput was $171( \pm 70)$ and $254( \pm 78)$ cows $/ \mathrm{h}$, the average labor efficiency at peak lactation was $100( \pm 43)$ and $162( \pm 74)$ cows/h/worker, and average row/rotation time was $10.2( \pm 2.7)$ and $11.8( \pm 2.5)$ $\mathrm{min}$, for herringbone and rotary parlors respectively.

General linear model and binary logistic regression (Proc GLM and Proc GLIMMIX, SAS 9.4, Cary, NC) were used to analyze the milking efficiency metrics (Table 2) and the probability of starting milking before $0500 \mathrm{~h}$. (on TAD farms). The models were sequential and included herd size (polynomial up to power of 3 , because not all milking efficiency metrics appeared linear), number of clusters, and their interaction as covariates, as well as milking once or twice a day (for milking time only) and parlor type as fixed factors. Backward elimination was used until only significant effects remained in the model. The analyses were weighted $(69 \%$ herringbone, $30 \%$ rotary) for the prevalence of these 2 main parlor types in the New Zealand dairy industry.

The effect of technology on milking efficiency metrics (Table 3) was analyzed using a mixed-models approach for repeated measures (morning and afternoon milking) ANOVA (Proc MIXED, SAS 9.4). The analysis was weighted for the prevalence of herringbone and rotary parlors and the model included number of clusters as a covariate, parlor type, automatic cluster removers (ACR), automatic teat sprayer, automatic drafter (also called automatic sorting) and all their interactions as fixed effects, milking session as a fixed effect, and farm as a random effect. Significant effects $(P \leq 0.05)$ are displayed as adjusted coefficients or least squares means and the associated standard error.

The results are presented in the order of the 7 key milking efficiency metrics described earlier. The analysis indicated that at peak lactation, the number of milkings per day (1 or 2 ), herd size, and the number of clusters determine the number of hours the parlor is harvesting milk (metric 1), irrespective of parlor type (Table 2). However, parlor type explained differences in the number of milking hours per worker per week (metric 2), with a higher number of hours associated with herringbone parlors (Figure 1a). For farms with a herringbone parlor, milking at peak lactation required $21-24 \mathrm{~h} /$ wk per worker, representing 52 to $58 \%$ of a 40-h work week or 42 to $47 \%$ of a 50 -h work week. In comparison, farms with a rotary parlor required 
17-20 h/wk per worker at peak lactation, representing 43 to $49 \%$ of a 40 -h work week or 34 to $39 \%$ of a 50 -h work week. The ranges depended on herd size and the number of clusters in the parlor. Eight percent of herds (across both shed types) were milked once a day (OAD) for the whole lactation, with milking at peak lactation requiring 11 to $14 \mathrm{~h} /$ wk per worker (28-35\% of a 40-h week) for farms with a herringbone parlor and 7 to $10 \mathrm{~h} /$ wk per worker (18- $25 \%$ of a $40-\mathrm{h}$ week) for farms with a rotary parlor.

The milking intervals (metric 3) used by survey participants at peak lactation varied with herd size, with larger herds using a shorter interval between morning and afternoon milkings (Table 2). The model predicted that small herds (e.g., 200 cows) are milked with 10and 14-h intervals, and larger herds (e.g., 800 cows) milked with 9.5- and 14.5-h intervals. Milking intervals were a significant factor associated with the probability of the morning milking starting before 5 a.m., along with herd size and the number of clusters (Figure 1b). The model predicted that larger herds could be milked without milking starting before $0500 \mathrm{~h}$ when a parlor had more clusters, or when 8- and 16-h milking intervals were used, relative to parlors with fewer clusters milking or a milking with a 10- and 14-h interval.

Significant variables affecting parlor throughput (metric 4), the number of cows milked per hour at peak lactation, were the number of clusters, the milking ses-

Table 3. Least squares means obtained from mixed model analysis for significant factors affecting a range of milking efficiency metrics

\begin{tabular}{|c|c|c|c|c|c|c|c|c|c|}
\hline \multirow{2}{*}{$\begin{array}{l}\text { Independent } \\
\text { variable }\end{array}$} & \multirow[b]{2}{*}{ Predictor variable } & \multirow[b]{2}{*}{ Time } & \multirow[b]{2}{*}{ Parlor $^{1}$} & \multirow[b]{2}{*}{$\mathrm{ACR}^{2}$} & \multirow[b]{2}{*}{ Drafter } & \multirow{2}{*}{$\begin{array}{l}\text { Teat } \\
\text { spray }\end{array}$} & \multicolumn{2}{|c|}{ Means } & \multirow[b]{2}{*}{$P$-value } \\
\hline & & & & & & & Estimate & $\mathrm{SE}$ & \\
\hline \multirow{4}{*}{$\begin{array}{l}\text { Throughput } \\
\text { (cows/h) } \\
\text { (Metric 4) }\end{array}$} & Clusters & & & & & & 5.2 & 0.20 & $<0.001$ \\
\hline & & $\mathrm{PM}$ & & & & & 232 & 4.0 & \\
\hline & $\mathrm{ACR} \times$ drafter & & & No & No & & $218^{\mathrm{ab}}$ & 5.4 & $<0.01$ \\
\hline & & & & No & Yes & & $248^{\mathrm{a}}$ & 11.1 & \\
\hline \multirow{9}{*}{$\begin{array}{l}\text { Labor efficiency } \\
\text { (cows/h per person) } \\
\text { (Metric 5) }\end{array}$} & Milking session & $\mathrm{AM}$ & & & & & 235 & 8.2 & $<0.001$ \\
\hline & & PM & & & & & 264 & 8.2 & \\
\hline & ACR $\times$ drafter & & & No & No & & $223^{\mathrm{b}}$ & 11.4 & $<0.05$ \\
\hline & & & & No & Yes & & $258^{\mathrm{ab}}$ & 23.4 & \\
\hline & & & & Yes & No & & $269^{\mathrm{a}}$ & 12.3 & \\
\hline & & & & Yes & Yes & & $247^{\mathrm{ab}}$ & 14.9 & \\
\hline & & & $\mathrm{R}$ & & No & Yes & $262^{\mathrm{ab}}$ & 17.1 & \\
\hline & & & $\mathrm{R}$ & & Yes & No & $259^{\mathrm{ab}}$ & 33.7 & \\
\hline & & & $\mathrm{R}$ & & Yes & Yes & $334^{\mathrm{a}}$ & 32.9 & \\
\hline \multirow{11}{*}{$\begin{array}{l}\text { Row/rotation time } \\
\text { (min) } \\
\text { (Metric 6) }\end{array}$} & Clusters & & & & & & 0.03 & 0.011 & $<0.01$ \\
\hline & Milking session & $\mathrm{AM}$ & & & & & 11.9 & 0.22 & $<0.001$ \\
\hline & & PM & & & & & 10.6 & 0.22 & \\
\hline & $\mathrm{ACR} \times$ drafter & & & No & No & & $11.5^{\mathrm{ab}}$ & 0.30 & $<0.05$ \\
\hline & & & & No & Yes & & $10.1^{\mathrm{b}}$ & 0.61 & \\
\hline & & & & Yes & No & & $11.6^{\mathrm{ab}}$ & 0.32 & \\
\hline & & & & Yes & Yes & & $11.9^{\mathrm{a}}$ & 0.39 & \\
\hline & Drafter $\times$ parlor type & & $\mathrm{H}$ & & No & & 11.1 & 0.34 & $<0.05$ \\
\hline & & & $\mathrm{H}$ & & Yes & & 11.6 & 0.39 & \\
\hline & & & $\mathrm{R}$ & & No & & 11.9 & 0.30 & \\
\hline & & & $\mathrm{R}$ & & Yes & & 10.4 & 0.62 & \\
\hline
\end{tabular}

\footnotetext{
a,b Means with no letters in common are significantly different at $P<0.05$.

${ }^{1} \mathrm{H}=$ herringbone, $\mathrm{R}=$ rotary.

${ }^{2} \mathrm{ACR}=$ automatic cluster removers. 
a)

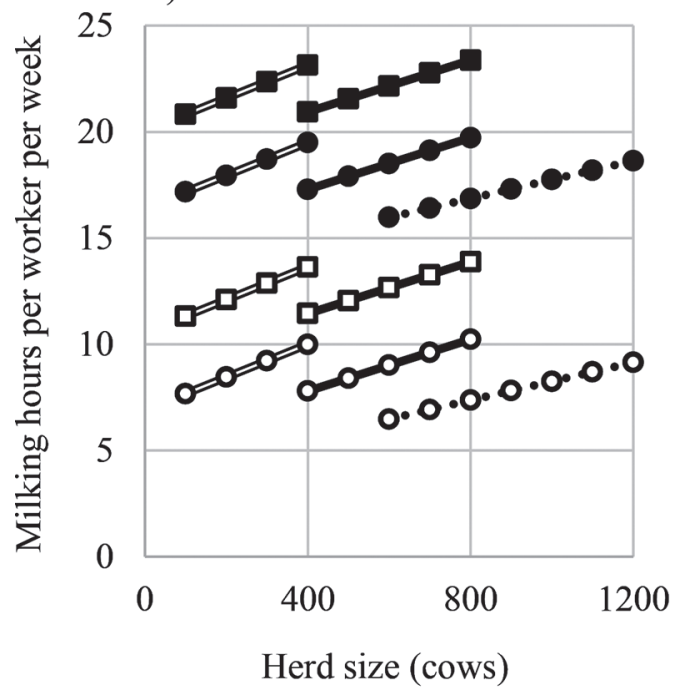

b)

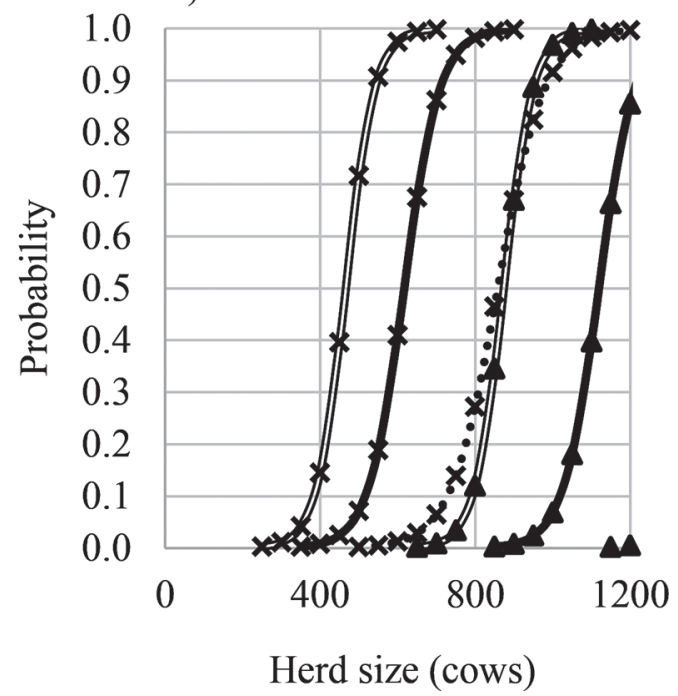

Figure 1. (a) The predicted number of milking hours per worker per week by herd size for a range of parlor types (herringbone $=$ square markers; rotary $=$ circle markers $)$, sizes $(20$ clusters $=$ double line; 40 clusters $=$ solid line; 60 clusters $=$ dotted line $)$, and milking regimens (milking once a day $=$ open markers; milking twice a day $=$ solid markers), and (b) the probability of milking starting before $0500 \mathrm{~h}$ by parlor size $(20$ clusters $=$ double line; 40 clusters $=$ solid line; 60 clusters $=$ dotted line $)$ and milking interval $(8$ to $16 \mathrm{~h}=$ triangle markers; 10 to 14 $\mathrm{h}=$ cross markers).

sion (morning/afternoon) and the interaction of ACR and automatic drafting (Table 3). Higher throughput was achieved at the afternoon milking, probably due to the shorter milking interval between morning and afternoon, which resulted in a lower milk yield in the afternoon. In parlors without ACR, an automatic drafter was associated with higher throughput $(P<$ 0.05 ) ; however, this was not the case when the parlor had ACR $(P=0.15)$. Farmers were not asked for the ACR removal threshold, as a previous survey indicated that $85 \%$ of the respondents did not know the answer (Edwards et al., 2015).

Additional factors were significant for labor efficiency at peak lactation (cows milked per hour per person; metric 5). Use of an automatic teat sprayer significantly increased labor efficiency by an average of 53 cows/person per hour. The interaction of ACR and automatic drafting was significant; having ACR and no automatic drafting improved labor efficiency compared with having neither $(P<0.05)$. Finally, the interaction of automatic drafting, parlor type, and automatic teat spraying was significant, with the inclusion of an automatic drafter appearing to negate the benefit of the automatic teat sprayer in herringbone parlors. In rotary parlors, having either an automatic drafter or automatic teat sprayer was associated with an increase in labor efficiency ( +40 to 43 cows/person per hour), but the combination of both was associated with an increase of 115 cows/person per hour (Table 3).
The number of clusters, milking session, interaction of ACR and automatic drafting, and interaction of automatic drafting and parlor type had significant effects on the time (min) taken to complete a row (herringbone) or rotation (rotary) at peak lactation (metric 6). The afternoon milking was associated with shorter average row/rotation times (by $1.3 \mathrm{~min}$ ). Having an automatic drafter and no ACR was associated with shorter average row/rotation times relative to having both technologies $(P<0.05$; Table 3$)$. The presence of ACR was associated with an increase in average row/ rotation time.

In herringbone parlors, the afternoon milking was associated with a shorter work routine time $(-2 \mathrm{~s} /$ cow; metric 7), which implies there likely is unused time (sometimes referred to idle time) for the milker(s) in the morning milking. There was also a significant interaction between automatic drafting and an automatic teat sprayer, with a faster work routine time associated with having an automatic teat sprayer and no automatic drafter (Table 3). Having an automatic teat sprayer was associated with an average of $3 \mathrm{~s} / \mathrm{cow}$ shorter work routine time.

Across the key milking efficiency metrics, several themes emerged. An automatic teat sprayer was associated with greater efficiency in the 2 metrics that relate to people, labor efficiency, and work routine time. An interaction involving automatic drafting was significant for all efficiency metrics and was associated 
with improved efficiency in rotary parlors but not in herringbone parlors. Automatic cluster removers were associated with longer milkings in terms of throughput (in combination with drafting) and average row/rotation time.

The current study was designed to be representative of the range of herd sizes and regional distribution dairy farm businesses nationally and used a large sample of randomly selected farmers relative to similar studies, which were based on non-randomized online snowball sampling methodology (Borchers and Bewley, 2015; Gargiulo et al., 2018). A limitation of this method, however, is that results are only a point in time and, therefore, have to be interpreted with appropriate caution. Nevertheless, the results provide useful insights into options for improving milking efficiency and workplace attractiveness of pasture-based dairy industries, as discussed in the following paragraphs.

The results illustrate the already established principle that the number of milking hours required for a herd is determined by the number of cows and number of clusters in the parlor (Table 2). This is because maximum potential throughput per cluster per hour is governed by the milking time of individual cows, though it can also be limited by cow flow into the parlor. Consequently, parlor type was not associated with throughput, and any perceptions that rotary parlors require less time to milk a herd is due to them having a greater average number of clusters (Edwards et al., 2015; Dela Rue et al., 2019). However, rotary parlors were associated with greater labor efficiency (Figure 1a), with a worker on a farm with a rotary parlor spending $3.65 \mathrm{~h}$ less milking per week at peak lactation than a worker on a farm with a herringbone parlor. This is discussed again later, but is largely because in a rotary parlor, compared with most herringbone parlors, cow loading and cow exiting can be automated using technology, which results in a shorter work routine time for the person(s) attaching clusters.

The results demonstrate that milking occupies a significant part of the week at peak lactation, contributing to unsociable work hours (starting before $0500 \mathrm{~h}$ ), and is likely the best option for reducing hours of work for dairy farm workers. This finding is supported by a recent Irish study (Deming et al., 2018). Given that, in most circumstances, it is not an option to change parlor type or the number of clusters, it is important to determine strategies and technologies for existing parlors to improve work hours and timing for dairy farm workers. One example is the use of a shorter milking interval between morning and afternoon milking, such as $8 \mathrm{~h}$ instead of $10 \mathrm{~h}$. This can be done without compromising milk production (McMeekan and Brumby, 1956; O'Brien et al., 1998) and means the morning milking can either start later or the afternoon milking can finish earlier (or both). In this study, the shorter milking interval was associated with a reduced probability of starting before $0500 \mathrm{~h}$ (Figure 1b), likely due to evening meal time creating a fixed end point, allowing the morning milking to begin later, thus increasing the attractiveness of the workplace.

Similarly, OAD milking, representing a 24-h milking interval, required $9.5 \mathrm{~h} /$ wk per worker less. However, a recent study indicated that, depending on herd characteristics, operating costs would need to be reduced to maintain profitability on farms adopting OAD (Edwards, 2018a). A subsequent study identified that labor was one category where this could be achieved, although this could offset the ability of OAD milking to reduce hours of work (Edwards, 2018b). The results of the present study indicate OAD could be effective at reducing hours worked on farm, but with an unknown effect on profitability.

Several technologies, and combinations of technologies are associated with milking efficiency. An automatic teat sprayer was associated with a shorter work routine time in herringbone parlors, and greater labor efficiency in both parlor types, although not when in combination with automatic drafting in a herringbone. In herringbone parlors, where the milkers usually undertake all parts of the milking routine (O'Brien et al., 2012), this positive association with an automatic teat sprayer is likely because it eliminates one task in the work routine. It is not immediately clear why automatic drafting appeared to negate the benefit of the teat sprayer, but it could be due to time taken to visually identify cow numbers to enter into the system rather than following cows visually (e.g., draft the third cow), which can be overcome in rotaries by using mirrors or in-bail ID readers. Despite its advantages, the adoption of automatic teat sprayers remains low in New Zealand herringbones at $10 \%$, with few farmers $(4 \%)$ considering installation (Dela Rue et al., 2019), which could indicate a need for the industry to demonstrate the effectiveness of the technology better. Similarly, in rotary parlors automatic teat spraying also eliminates a task, but because this task occurs at a different location in the parlor to cluster attachment its effect may depend on other technologies installed. For example, in a rotary, having both automatic teat spraying and ACR allows the parlor to operate without a milker in the cluster removing position, and is likely why these are the most common technologies in rotaries; $70 \%$ have automatic teat spraying, and $77 \%$ have ACR (Dela Rue et al., 2019). Two economic analyses concluded that ACR and an automatic teat sprayer were beneficial in rotary parlors (Tarrant and Armstrong, 2012; Edwards et al., 2014a), although Tarrant and Armstrong (2012) 
noted mastitis detection could be more challenging without a person at the cluster removing position.

The case for ACR in swing-over herringbone parlors may not be as strong as the milker must still pick up and swing the cluster over from the middle of the pit, negating much of the potential time saving. Overmilking would be prevented, allowing a milker to handle more clusters, but unless they were able to decrease another part of their work routine time, this would only result in additional cluster idle time in block calving systems, rather than improved throughput, unless another milker was added, which would likely decrease labor efficiency (Edwards et al., 2013c). Additionally, with ACR, the decision of when to end milking (remove cluster) is taken from the milker; in these results ACR were associated with longer average row/rotation times. One explanation is that when the milker makes the decision to remove the cluster this is usually earlier than the ACR, similar to applying a maximum milking time strategy (Jago et al., 2010).

In herringbone parlors, the afternoon milking was associated with a shorter work routine time, and in both parlor types was associated with a shorter row/ rotation time and greater throughput. This result is probably due to the milking interval resulting in less milk to harvest in the afternoon (O'Brien et al., 1998) and indicates that milkers are likely to have unused time, waiting for cows to finish milking, at the morning milking. This presents an opportunity to improve labor efficiency by applying a maximum milking time (Jago et al., 2010) or increasing the ACR flow rate removal threshold (Edwards et al., 2013b), as ACRs were associated with longer average row/rotation times indicating their settings may be resulting in the clusters remaining on cows longer than necessary. Further evidence of this opportunity are the row/rotation times being 4 min slower than the milking time of the 80th percentile (the maximum milking time threshold) of New Zealand cows at peak milk production (Edwards et al., 2014b; LIC and DairyNZ, 2019).

In summary, our results highlight that milking represents a significant part of the working week on many farms at peak lactation, depending on herd size, the number of clusters, and milking frequency. Therefore, improving milking efficiency is a key requirement to achieving farmer goals of reducing hours of work and building workplaces competitive with other sectors. There is a considerable opportunity to improve efficiency from the perspective of milking and parlor management (e.g., 8- and 16-h milking intervals or OAD) and technology use. Technology or combinations of technologies associated with improved efficiency depend on parlor type and include automatic teat spraying (herringbone and rotary) and automatic drafting (rotary). However, the results indicate that automation technology is not always associated with greater efficiency, highlighting the need for sound evaluation for individual farm situations, acknowledging that there may be additional drivers for installing technologies other than milking efficiency. This study provides useful data for those wishing to analyze the likely value of in-parlor automation technology or management practices for an individual farm situation.

\section{ACKNOWLEDGMENTS}

This work was funded by New Zealand Dairy Farmers through DairyNZ, Inc. (Hamilton, New Zealand), contract WEN1802. We thank S. Cuthbert (Cuthbert \& Associates, Hamilton, New Zealand) for assistance with survey design and for conducting surveys. The authors have not stated any conflicts of interest.

\section{REFERENCES}

Borchers, M. R., and J. M. Bewley. 2015. An assessment of producer precision dairy farming technology use, prepurchase considerations, and usefulness. J. Dairy Sci. 98:4198-4205. https://doi .org/10.3168/jds.2014-8963.

Burke, J. K., and J. G. Jago. 2011. Comparing somatic cell counts, production and milking durations of dairy cows when milked at two automatic cup removal flow-rate thresholds. Anim. Prod. Sci. 51:920-924. https://doi.org/10.1071/AN11042.

Dairy Tomorrow. 2018. The dairy industry strategy 2017-2025. Accessed Aug. 27, 2018. https://www.dairytomorrow.co.nz/wp -content/uploads/2017/12/dairy-strategy-2017-A4-booklet-Part3 .pdf.

Dela Rue, B. T., C. R. Eastwood, J. P. Edwards, and S. Cuthbert. 2019. New Zealand dairy farmers preference investments in automation technology over decision-support technology. Anim. Prod. Sci. 60:133-137. https://doi.org/10.1071/AN18566.

Deming, J., D. Gleeson, T. O'Dwyer, J. Kinsella, and B. O'Brien. 2018. Measuring labor input on pasture-based dairy farms using a smartphone. J. Dairy Sci. 101:9527-9543. https://doi.org/10 .3168/jds.2017-14288.

Eastwood, C. R., J. Greer, D. Schmidt, J. Muir, and K. Sargeant. 2018. Identifying current challenges and research priorities to guide the design of more attractive dairy-farm workplaces in New Zealand. Anim. Prod. Sci. 60:84-88. https://doi.org/10.1071/AN18568.

Edwards, J. P. 2018a. Comparison of milk production and herd characteristics in New Zealand herds milked once or twice a day. Anim. Prod. Sci. 59:570-580. https://doi.org/10.1071/AN17484.

Edwards, J. P. 2018b. A comparison of profitability between farms that milk once or twice a day. Anim. Prod. Sci. 60:102-106. https: //doi.org/10.1071/AN18528.

Edwards, J. P., B. T. Dela Rue, and J. G. Jago. 2014. Evaluating rates of technology adoption and milking practices on New Zealand dairy farms. Anim. Prod. Sci. 55:702-709. https://doi.org/10 .1071/AN14065.

Edwards, J. P., J. G. Jago, and N. Lopez-Villalobos. 2013a. Short-term application of pre-stimulation and increased automatic cluster remover threshold affect milking characteristics of grazing dairy cows in late lactation. J. Dairy Sci. 96:1886-1893. https://doi.org/ $10.3168 / j d s .2012-6191$.

Edwards, J. P., J. G. Jago, and N. Lopez-Villalobos. 2013b. Milking efficiency for grazing dairy cows can be improved by increasing automatic cluster remover thresholds to grazing dairy cows without applying pre-milking stimulation. J. Dairy Sci. 96:3766-3773. https://doi.org/10.3168/jds.2012-6394. 
Edwards, J. P., J. G. Jago, and N. Lopez-Villalobos. 2014a. Principles for maximising operator efficiency and return on investment in rotary dairies. Anim. Prod. Sci. 54:1102-1108. https://doi.org/10 1071/AN13200.

Edwards, J. P., J. G. Jago, and N. Lopez-Villalobos. 2014b. Analysis of milking characteristics in New Zealand dairy cows. J. Dairy Sci 97:259-269. https://doi.org/10.3168/jds.2013-7051.

Edwards, J. P., B. O'Brien, N. Lopez-Villalobos, and J. G. Jago. 2013c. Milking efficiency of swingover herringbone parlours in pasture-based dairy systems. J. Dairy Res. 80:467-474. https:// doi.org/10.1017/S0022029913000393.

Gargiulo, J. I., C. R. Eastwood, S. C. Garcia, and N. A. Lyons. 2018. Dairy farmers with larger herd sizes adopt more precision dairy technologies. J. Dairy Sci. 101:5466-5473. https://doi.org/10 .3168/jds.2017-13324.

Jago, J. G., J. K. Burke, and J. H. Williamson. 2010. Effect of automatic cluster remover settings on production, udder health, and milking duration. J. Dairy Sci. 93:2541-2549. https://doi.org/10 .3168/jds.2009-2949.

LIC (Livestock Improvement Corp) and DairyNZ. 2019. New Zealand dairy statistics 2018-19. LIC and DairyNZ, Hamilton, New Zealand. Accessed Dec. 12, 2019. https://www.dairynz.co.nz/media/ 5792393/nz-dairy-statistics-2018-19-web.pdf.

McMeekan, C. P., and P. J. Brumby. 1956. Milk production and interval between milking. Nature 178:799. https://doi.org/10.1038/ 178799a0.

O'Brien, B., J. G. Jago, J. P. Edwards, N. Lopez-Villalobos, and F. McCoy. 2012. Milking parlour size, pre-milking routine and stage of lactation affect efficiency of milking in single-operator herringbone parlours. J. Dairy Res. 79:216-223. https://doi.org/10.1017/ S0022029912000088.
O'Brien, B., J. O'Connell, and W. J. Meaney. 1998. Short-term effect of milking interval on milk production, composition and quality. Milchwissenschaft 53:123-126.

Rutten, C. J., W. Steeneveld, A. G. J. M. Oude Lansink, and H. Hogeveen. 2018. Delaying investments in sensor technology: The rationality of dairy farmers' investment decisions illustrated within the framework of real options theory. J. Dairy Sci. 101:7650-7660. https://doi.org/10.3168/jds.2017-13358.

Tarrant, K. A., and D. P. Armstrong. 2012. An economic evaluation of automatic cluster removers as a labour saving device for dairy farm businesses. AFBM J. 9:43-48. https://doi.org/10.22004/ag .econ. 131752

Taylor, G., L. van der Sande, and R. Douglas. 2009. Smarter not harder: Improving labour productivity in the primary sector. Accessed Jun. 30, 2013. http://maxa.maf.govt.nz/sff/about-projects/ search/05-028/technical-report.pdf.

Teagasc. 2018. People in Dairy Action Plan. Accessed Oct. 27, 2019. https://www.teagasc.ie/media/website/publications/2018/People -in-Dairy-Action-Plan.pdf.

Thomas, E. B., K. A. Dolecheck, T. B. Mark, C. R. Eastwood, B. T. Dela Rue, and J. M. Bewley. 2019. A decision-support tool for investment analysis of automated oestrus detection technologies in a seasonal dairy production system. Anim. Prod. Sci. 59:2280-2287. https://doi.org/10.1071/AN17730.

\section{ORCIDS}

J. P. Edwards () https://orcid.org/0000-0003-4220-7408

B. Kuhn-Sherlock @ https://orcid.org/0000-0002-1890-0301

C. R. Eastwood (1) https://orcid.org/0000-0002-1072-5078 